\title{
Research Paper: The Role of Negative Affects and Emotion Dysregulation in Aggression
}

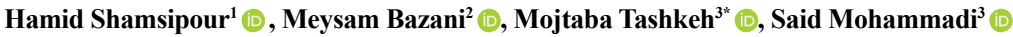

1. Department of Psychology, School of Psychology and Education, University of Tehran, Tehran, Iran.

2. Department of Clinical Psychology, Student Research Committee, Shahid Beheshti University of Medical Sciences, Tehran, Iran.

3. Mental Health Research Center, School of Behavioral Sciences and Mental Health (Tehran Institute of Psychiatry), Iran University of Medical Sciences, Tehran, Iran.

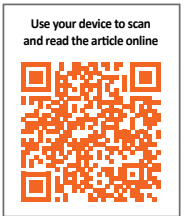

Citation: Shamsipour, H., Bazani, M., Tashkeh, M., \& Mohammadi, S. (2018). The Role of Negative Affects and Emotion Dysregulation in Aggression. Journal of Practice in Clinical Psychology, 6(4), 249-256. http://dx.doi.org/10.32598/jpcp.6.4.249

doif: http://dx.doi.org/10.32598/jpcp.6.4.249

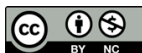

Fundling: See Page 255

Article info:

Received: 26 Feb 2018

Accepted: 10 Jun 2018

Available Online: 01 Oct 2018

Keywords:

Aggression, Emotional disturbance, Affect

\section{ABSTRACT}

Objective: Emotion dysregulation, negative affects, and aggression can affect each other. This study aimed to demonstrate the role of the negative effects and emotion dysregulation in aggressio.

Methods: The statistical population was Kharazmi University students that 280 of them were selected by random multiphasic sampling method. The study instruments were Buss-Perry aggression questionnaire, the short form of cognitive emotion regulation questionnaire and positive affect and negative affect scale. The Pearson correlation, Student $t$ test, and hierarchical regression tests were used to analyse the data.

Results: Gender, negative affect and maladaptive emotion regulation strategies (rumination, catastrophizing, and others blaming) were correlated with aggression. After controlling for gender and negative affect, maladaptive emotion regulation explained only $0.029 \%$ of the aggression variance and in this case and negative affect could explain $11.4 \%$ of its variance. Furthermore, by controlling for gender and negative affect, others blaming and catastrophizing strategies could explain $0.077 \%$ of the aggression variance.

Conclusion: This study demonstrates the more important role of negative affect in predicting aggression. It seems that efficient methods to improve mood state can be helpful in aggression reduction.

\section{* Corresponding Author:}

Mojtaba Tashkeh, MSc.

Address: Mental Health Research Center, School of Behavioral Sciences and Mental Health (Tehran Institute of Psychiatry), Iran University of Medical Sciences, Tehran, Iran.

Tel: +98 (990) 1913252

E-mail:mojtabatashkeh@gmail.com 


\section{Highlights}

- There is a relationship between aggression and negative affect and emotion dysregulation.

- Negative affect is stronger in predicting aggression than emotion dysregulation.

- The role of negative affect is greater than gender and negative emotion regulation in aggression.

\section{Plain Language Summary}

We know that emotion dysregulation, negative affects, and aggression can affect each other. However, it is unclear that how and to what extent emotion dysregulation and negative affect can predict aggression. This fact can be very important in helping people with problems in aggression control. Therefore, this study conducted to demonstrate the role of negative affect and emotion dysregulation in aggression. The study participants were Kharazmi University students in Tehran, Iran. Of them, 280 were randomly selected. The study instruments were Buss-Perry aggression questionnaire, the short form of cognitive emotion regulation questionnaire, and positive and negative affect scale. Gender, negative affect and maladaptive emotion regulation strategies (rumination, catastrophizing, and others blaming) had significant correlation with aggression.

After controlling for gender and negative affect, maladaptive emotion regulation explained a very small part of aggression variance that was not statistically significant but negative affect could explain considerable amount of aggression variance beyond gender and maladaptive emotion regulation. This study demonstrated the more important role of negative affect in predicting aggression. It seems that efficient methods to improve mood state can be more effective in helping people reduce their aggressive behaviors than efforts to reduce maladaptive emotion regulation strategies or teaching constructive methods of emotion regulation.

\section{Introduction}

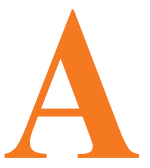

ggression is a human behavioral pattern that manifests in different ways (Colakoglu \& Solak, 2014) and its relationship with negative affects has a long history (Miller \& Lynam, 2006). Negative affect refers to a tendency to experience negative emotions in different situations, even in the absence of any obvious stressful factors (Watson \& Clark, 1984). In fact, tendency to experience negative affect is a fundamental issue from an evolutionary perspective of externalizing disorders (Waldman, Singh, \& Lahey, 2006).

Negative excitability in teenagers predicts antisocial behavior and antisocial personality disorder, consequently (Krueger, 1999). Similarly, negative affect variables are associated with aggression in adults (Miller, Zeichner, \& Wilson, 2012). Some evidence indicates that the relationship between aggression and neuroticism is somewhat related to increased aggressive emotions (Barlett \& Anderson, 2012). Studies have addressed the underlying mechanisms of the relationship between negative affect and aggression to clarify how they are related. Emotion regulation is an important variable (Werner \& Gross, 2010).

Emotion regulation includes a wide range of internal and external processes, used for reviewing, evaluating, and modifying the emotional reactions. In addition, it includes a broad range of cognitive, behavioral, emotional, and physical responses and is necessary for understanding the emotional and behavioral correlates of stress and negative affective states (Garnefski \& Kraaij, 2006). Studies reported that emotion regulation can mediate the relationship between negative affect and aggression (Roberton, Daffern, \& Bucks, 2012).

Generally, emotion dysregulation is known as a mechanism by which negative affects influence psychopathology. The Calkins' evolutionary theory of emotion regulation (Calkins, 1994) claims that individual differences like emotion regulation skills modify the effect of behavioral features (e.g. this claim, Kim-Spon et al. (Kim-Spoon, Cicchetti, \& Rogosch, 2013) conducted a longitudinal study on children with and without history of misbehavior. They concluded that emotion regulation modifies the relationship between emotional instability, negativism and externalizing symptoms. Similarly, 
emotion regulation appears to relatively modify the relationship between anger rumination and reactive aggression (White \& Turner, 2014). Moreover, some studies concluded that maladaptive emotion regulation leads to aggression through the increased experience of negative affect (Roberton et al., 2012).

Megargee suggested that people, who overcontrol their emotions, experience more severe aggression compared to those with low control on their emotions, because the excessive control makes them experience higher levels of aggression and arousal of unpleasant emotions (Megargee, 1966). The intense suppression of anger had a direct relationship with aggressive behaviors (Norström \& Pape, 2010). Another study showed that the above-mentioned maladaptive ways to control anger were predictors of aggressive behavior (Tull, Barrett, McMillan, \& Roemer, 2007). Wyckoff (2016) reviewed previous studies on negative emotion and concluded that although many psychologists have theorized that negative emotions lead to aggression, the triggering context of these emotions and how such emotions predict aggression, remains unclear.

An overview of the literature reveals that most studies conducted in recent decades have attempted to describe and explain the behavioral nature of this phenomenon. A few research demonstrated the role of emotional factors in predicting aggression. However, many researchers have emphasized on emotions derived from frustration, as an underlying factor in aggression and suggest that dimensions of emotions can play an important role in aggression (Roberton et al., 2012). In this regard, further research is needed to identify predictive factors for aggression. This research aimed to investigate the role of negative affect in predicting aggression, as well as the role of emotion dysregulation in predicting aggression beyond the negative affect.

\section{Methods}

The statistical population consisted of the students of Kharazmi University of Tehran. Of them, 280 students were selected using a multistage random sampling method. Out of the university faculties (psychology and Education, Mathematical Sciences, Engineering, Physical Education, Literature and Languages, Biological Sciences, and Chemistry), 3 faculties were randomly selected. Then, 8 classrooms were randomly selected from those faculties. Questionnaires were provided to the students. Final sample size was 260, because 20 questionnaires were incomplete and discarded. Firstly, a brief instruction was provided on how to answer the questions. It was explained that the personal information of students, including their names are not needed to be written in the questionnaires, and the collected data would be used only for research purposes.

All participants' data remained confidential throughout the study. Then, the students completed the questionnaires in 15 to 20 minutes. The questionnaires were implemented in 4 weeks. The data were analyzed by statistical methods of point-biserial correlation, the Pearson correlation coefficient, Student's t test, and hierarchical regression, using SPSS-20.

Data collection tools include: 1. Buss-Perry Aggression Questionnaire (BP-AQ) which is the new version of hostility questionnaire (Buss \& Perry, 1992) with 29-item self-report instrument in 4 subscales. The subscales include Physical Aggression (PA), Verbal Aggression (VA), Anger (A), and Hostility (H). The subjects answered each item on a 5-point Likert-type scale: 1. Extremely uncharacteristic of me; 2. Somewhat uncharacteristic of me; 3. Uncertain; 4. Somewhat characteristic of me; and 5. Extremely characteristic of me. The items number 9 and 16 are scored reversely. The total score of aggression is obtained by sum of scores of all subscales. The test-retest reliability and the correlation coefficients of the questionnaire were found as $0.80,0.76,0.72$, and 0.72 , respectively for physical aggression, verbal regression, aggression, and hostility. The Cronbach's alpha coefficient, split-half reliability, and test-retest reliability of the questionnaire have been reported as $0.89,0.78$, and 0.73 , respectively, in Iran. The Cronbach's alpha coefficients for hostility, physical aggression, verbal aggression, aggression, and hostility were $0.82,0.79,0.74$, and 0.71, respectively (Bakhtiyari, Tashkeh, Bazani, \& Mohammadi, 2016). In this study, only the total test score was used and Cronbach's alpha coefficient for it was 0.82 .

2. Cognitive Emotion Regulation Questionnaire, short version (CERQ-short) which is a 18-item questionnaire was developed by Garnefski and Kraaij (2007). Each item is answered on a 5-point Likert-type scale $(1=$ almost never to $5=$ almost always). It is a multi-dimensional scale and used to identify the coping cognitive strategies after an adverse event. In addition to adaptive and maladaptive emotion regulation styles, this questionnaire measures different strategies of each style. Adaptive emotion regulation style includes positive refocusing, refocus on planning, positive reappraisal, and putting into perspective. Maladaptive emotion regulation strategies consist of self-blame, other-blame, rumination, acceptance, and catastrophizing. The Cronbach's alpha coef- 
ficients for the 9 subscales of this questionnaire with a range of 0.68 to 0.82 , indicating the acceptable reliability of the questionnaire. In addition, the 9-factor structure of CERQ-short has been approved by principal component analysis, and those 9 factors are accountable for a major part of data variance (75\%) (Hasani, 2011). In the present study, the Cronbach's alpha coefficient for total negative emotion regulation was 0.63 and varied from 0.53 to 0.75 for the 5 subscales of this variable.

3. Positive and Negative Affect Schedule (PANAS) which is a 20 -item self-report tool, was designed for measuring the dimensions of negative and positive affect. Each dimension has 10 items and is scored on a 5 -point Likert-type scale (from $1=$ very low to $5=$ very high). Its internal consistency coefficient (Cronbach's alpha) was 0.88 for the positive affect and 0.87 for the negative affect (Watson, Clark, \& Tellegen, 1988). The internal consistency coefficient of the Persian version of this scale (Bakhshipour \& Dezhkam, 2006) was obtained as 0.87 for both subscales on Iranian population. Our study only used the negative affect dimension with reliability coefficient of 0.86 .

\section{Results}

\section{Primary analysis}

Demographic characteristics of participants is presented in Table 1. Only gender had a significant negative correlation with aggression $(\mathrm{r}=-0.169, \mathrm{P}<0.01)$. Males had a higher level of aggression, compared to females $(\mathrm{t}=2.7$, $\mathrm{P}<0.01)$. The Pearson correlation coefficient was used to determine the degree of correlation between aggression and negative affect, maladaptive emotion regulation, and its 5 subscales. The results of Pearson's correlation analysis and descriptive statistics related to variables are listed in Table 2.

As shown, aggression has a correlation with negative affect and maladaptive emotion regulation among the strategies of maladaptive emotion regulation, while selfblame, and acceptance had no significant correlations with aggression. Thus, these two variables were not entered in the hierarchical regression analysis. In order to analyze the hierarchical regression, gender and negative affect were initially entered into the model.

\section{Regression analysis}

\section{Gender and negative affect}

As mentioned, gender and negative affect variables were included in the model. The results indicated that these 2 variables had a significant role in the model $\left(\mathrm{F}_{2,259}=35.466\right.$, $\mathrm{P}=0.001)$ and explained $21.6 \%$ of aggression variance. In other words, gender $(\mathrm{t}=-2.372, \mathrm{~B}=-0.131, \mathrm{P}=0.01)$ and negative affect $(\mathrm{t}=7.938, \mathrm{~B}=-0.439 \mathrm{P}=0.001$, $)$ had a significant relationship with aggression. In the second step, the negative emotion regulation was entered into the model. It also had a significant role in the model $\left(\mathrm{F}_{2,259}=28.996\right.$, $\mathrm{P}=0.001$ ), and explained the $0.029 \%$ of the aggression vari-

Table 1. Demographic characteristics of study participants

\begin{tabular}{ccc}
\hline & & No. (\%) \\
\hline Gender & Men & 151(56.8) \\
\hline Age, $y$ & Women & 112(43.25) \\
& $18-57$ (Range) & 200(76) \\
\hline Education & BA student & 59(29.4) \\
& MA student & $4(1.6)$ \\
\hline History of aggression & PhD student & $57(22.8)$ \\
& & $93(365)$ \\
& First & $52(22.95)$ \\
\hline Birth order & Second & $43(16.7)$ \\
& Third & 29(11.2) \\
& Fourth & $43(13.2)$ \\
\hline
\end{tabular}


Table 2. Correlation coefficient matrix among studied variables

\begin{tabular}{|c|c|c|c|c|c|c|c|c|}
\hline & $\mathrm{Ag}$ & N.E & M.E.R & S.B & O.B & $\mathbf{R}$ & A & C \\
\hline $\mathrm{Ag}$ & 1 & & & & & & & \\
\hline NE & 0.451 & 1 & & & & & & \\
\hline MER & 0.343 & 0.367 & 1 & & & & & \\
\hline SB & 0.095 & 0.089 & 0.424 & 1 & & & & \\
\hline $\mathrm{OB}$ & 0.318 & 0.208 & 0.480 & 0.105 & 1 & & & \\
\hline $\mathrm{R}$ & 0.172 & 0.215 & 0.627 & 0.038 & 0.146 & 1 & & \\
\hline A & 0.016 & 0.126 & 0.563 & 0.082 & 0.026 & 0.256 & 1 & \\
\hline C & 0.367 & 0.394 & 0.716 & 0.352 & 0.117 & 0.322 & 0.215 & 1 \\
\hline Mean $\pm S D$ & $4.80 \pm 1.9$ & $5.20 \pm 1.8$ & $6.48 \pm 1.8$ & $4.21 \pm 1.7$ & $5.25 \pm 1.9$ & $25.96 \pm 5.3$ & $23 \pm 7.4$ & $44.75 \pm 16.7$ \\
\hline
\end{tabular}

Abbreviations: Ag: Aggression; NE: Negative affect; MER: Maladaptive Emotion Regulation; SB: Self-Blame; OB: Others Blame; R: Rumination; A: Acceptance; C: Catastrophizing.

ance $(\mathrm{t}=3.578, \mathrm{~B}=-0.208, \mathrm{P}=0.001)$. It seems that the role of maladaptive emotion regulation beyond gender and negative affect was not considerable.

\section{Maladaptive emotion regulation strategies}

In order to determine the role of each maladaptive emotion regulation strategy, more exploratory analyses were conducted. After controlling the gender and negative affect in the first step, 3 strategies with a significant correlation to aggression, were entered into the model $\left(\mathrm{F}_{5,259}=21.060\right.$, $\mathrm{P}=0.001$ ) that explained $0.077 \%$ of the aggression variance. Particularly, other-blame $(\mathrm{t}=3.424, \mathrm{~B}=-0.193, \mathrm{P}=0.001$, and catastrophizing $(\mathrm{t}=2.390, \mathrm{~B}=0.149, \mathrm{P}=0.05)$ had a significant relationship with aggression, while this was not true about rumination $(\mathrm{P}=0.369)$.

Gender, maladaptive emotion regulation and negative affect

In the next stage of analysis, gender and negative emotion regulation were initially entered into the model, with a significant role in the model $\left(\mathrm{F}_{2,259}=20.87\right.$, $\mathrm{P}=0.001$ ) that explained $0.14 \%$ of the aggression variance. In other words, gender $(\mathrm{t}=-2.688, \mathrm{~B}=-0.156$, $\mathrm{P}=0.01$, and maladaptive emotion regulation $(\mathrm{t}=5.875$, $\mathrm{B}=0.340, \mathrm{P}=0.001$, ) had a significant relationship with aggression. In the second step, the negative affect was entered into the analysis, with a significant role in the model $\left(\mathrm{F}_{2,258}=28.997, \mathrm{P}=0.001\right.$, $)$ that explained the other $11.4 \%$ of the aggression variance $(\mathrm{t}=3.578, \mathrm{~B}=0.208$, $\mathrm{P}=0.001)$. Therefore, the role of negative affect beyond gender and negative emotion regulation was much more considerable than the role of maladaptive emotion regulation beyond gender and negative affect.

\section{Discussion}

Our results indicated the relationship between emotion regulation and negative affect on aggression. Gender and negative affect variables explained $21.6 \%$ of aggression variance and after controlling, maladaptive emotions explained less than $1 \%$ of aggression variance. Also, after controlling gender and maladaptive emotion regulation, the negative affect could explain $11.4 \%$ of aggression variance and played a stronger role in this regard. Negative affect beyond gender and negative emotion regulation had a much higher role than maladaptive emotion regulation beyond gender and negative affect. Based on the general model of aggression, research findings supported this notion that current internal state characterized by experiencing unpleasant emotions and inability to manage them, dispose people to commit aggressive behaviors (Anderson \& Bushman, 2002). In fact, when negative emotions overcome a person, he/she performs aggressive actions to suppress these emotions or avoid them (Roberton et al., 2012).

Our findings are somewhat inconsistent with the study by Donahue, Goranson, McClure and Van Male (2014) that stated some aspects of emotion dysregulation affect the relationship between negative affect and aggression, while their alternative hypothesis sug- 
gesting the mediating role of negative affect on the relationship between maladaptive emotion regulation and physical aggression, was not supported. However, only physical aggression was considered in their study, while our study considered aggression in general. In addition, the previous study had an acceptance-oriented approach to maladaptive emotion regulation, using the Difficulties in Emotion Regulation Scale (DERS), which differs from instruments used to measuring maladaptive emotion regulation.

Finally, both studies had been conducted in a nonclinical setting and the mentioned inconsistency of study results could represent complexity and multidimensionality of the relationship between aggression, negative affect and aggression, something that calls for further studies. Moreover, after controlling gender and negative affect in the first step, 2 maladaptive emotion regulation strategies (others-blame and catastrophizing) showed significant relationship with aggression. It seems that these findings were consistent with the previous research, stating that the mood state affects cognitive performance and information processing.

Once individuals experience an emotion like anger, aggressive thoughts become active, aggressive schemas become dominant (Berkowitz, 1990), and their attention directs toward the information related to anger (Eckhardt $\&$ Cohen, 1997). Thus, the negative affective state may dispose people to aggression through their evaluation of situations and interference with information processing (Rydell et al., 2008). Thus, it can be expected that the high levels of negative affect make the susceptible people to catastrophically interpret a situation and inappropriately evaluate their responsibilities in overcoming their aggressive behavior.

Mennin, Heimberg, Turk, and Fresco (2005) conducted an investigation to determine the emotional components of emotion dysregulation in the psychopathology of anxiety and depression. Based on their results, four factors of emotional intensity, poor understanding of emotions, negative reaction to emotions and maladaptive management of emotions were reveled in the common tools used to measure the emotions functioning and their dysregulation. It was also found that the factors of poor understanding of emotions, negative reactions to emotions and maladaptive management of emotions, were related to the hidden factor of emotion dysregulation. The emotional intensity was better identified, separately. This suggests that this factor may be an important factor and people with high emotional intensity are susceptible to psychological disturbances, due to their physical characteristics.

In the theoretical model, it is believed that people with mental disorders have a temperamental susceptibility for these disorders. This factor is related to emotions and emotion dysregulation. In fact, the negative affect can lead to maladaptive regulation strategies, and maladaptive strategies can in turn lead to higher levels of negative affect (Mennin, Holaway, Fresco, Moore, \& Heimberg, 2007). This model can also explain the problems of people with aggressive behaviors.

The present study had some limitations, too. First, studying aggression in a non-clinical sample of university students limits the generalization of findings. Thus, we propose that future studies address variables affecting aggression in clinical populations. Second, the study data were collected using self-report questionnaires that are probably not the best method for evaluating aggression. Using state-centered measurements for evaluating the aggression and negative affect could yield more valuable information. In addition, studying the diverse kinds of aggression and inclusion of other variables, such as the ability to tolerate frustration and positive affect, can help better understand the problem, because the previous research studies have shown that invoking anger had a positive relationship with enhanced positive mood (Harmon-Jones, Harmon-Jones, Abramson, \& Peterson, 2009) and maladaptive emotion regulation of positive emotions could be another route toward aggression. Finally, the correlational nature of the present study makes it impossible to infer causal conclusions and indicates the need for longitudinal investigations.

The findings indicate the importance of negative affect and to a lesser degree the maladaptive emotion regulation effect on aggression. Notably, the strategies of catastrophizing and others-blame are of a greater importance. Thus, in order to reduce client's aggressive behavior, clinicians should focus on helping them to initially experience less negative affect, by educating efficient strategies of problem-solving and decision making, particularly in interpersonal contexts, problem-focused stress-management skills, and correcting cognitive distortions.

The present study demonstrated the importance of negative emotions in predicting aggression. These results could provide researchers an opportunity to conduct future research and a clinical guide to identify and address the factors influencing aggressive behavior management. 


\section{Ethical Considerations}

\section{Compliance with ethical guidelines}

All ethical principles were considered in this article. The participants were informed about the purpose of the research and its implementation stages; They were also assured about the confidentiality of their information; Moreover, They were allowed to leave the study whenever they wish, and if desired, the results of the research would be available to them.

\section{Funding}

This research did not receive any specific grant from funding agencies in the public, commercial, or not-forprofit sectors.

\section{Conflict of interest}

The authors certify that they have no affiliation with or involvement in any organization or entity with any financial interest, or non-financial interest in the subject matter or materials discussed in this manuscript.

\section{Acknowledgements}

Authors would like to thank all the participants who provided the opportunity to conduct this research.

\section{References}

Anderson, C. A., \& Bushman, B. J. (2002). Human aggression. Annual Review of Psychology, 53, 27-51. [DOI:10.1146/annurev. psych.53.100901.135231] [PMID]

Bakhshipour, R., \& Dezhkam, M. (2006). A confirmatory factor analysis of the Positive Affect and Negative Affect Scales (PANAS). Clinical Neurology and Neurosurgery, 108(5), 477-81. [PMID]

Bakhtiyari, M., Tashkeh, M., Bazani, M., \& Mohammadi, S, (2016). [Relationship between cognitive emotion regulation and aggression: Role of gender (Persian)]. Pajoohande, 21(5), 305-12.

Barlett, C. P., \& Anderson, C. A. (2012). Direct and indirect relations between the Big 5 personality traits and aggressive and violent behavior. Personality and Individual Differences, 52(8), 870-5. [DOI:10.1016/j.paid.2012.01.029]

Berkowitz, L. (1990). On the formation and regulation of anger and aggression: A cognitive-neoassociationistic analysis. American Psychologist, 45(4), 494-503. [DOI:10.1037/0003066X.45.4.494] [PMID]
Buss, A. H., \& Perry, M. (1992). The aggression questionnaire. Journal of Personality and Social Psychology, 63(3), 452-9. [DOI:10.1037/0022-3514.63.3.452] [PMID]

Calkins, S. D. (1994). Origins and outcomes of individual differences in emotion regulation. Monographs of the Society for Research in Child Development, 59(2-3), 53-72. [DOI:10.2307/1166138]

Colakoglu, F. F., \& Solak, N. (2014). Examination of aggression levels and empathic tendency levels of secondary school students who involve or not involve in sports. ProcediaSocial and Behavioral Sciences, 152, 415-20. [DOI:10.1016/j.sbspro.2014.09.223]

Donahue, J. J., Goranson, A. C., McClure, K. S., \& Van Male, L. M. (2014). Emotion dysregulation, negative affect, and aggression: A moderated, multiple mediator analysis. Personality and Individual Differences, 70, 23-28. [DOI:10.1016/j. paid.2014.06.009]

Eckhardt, C. I., \& Cohen, D. J. (1997). Attention to anger-relevant and irrelevant stimuli following naturalistic insult. Personality and Individual Differences, 23(4), 619-29. [DOI:10.1016/S01918869(97)00074-3]

Garnefski, N., \& Kraaij, V. (2006). Relationships between cognitive emotion regulation strategies and depressive symptoms: A comparative study of five specific samples. Personality and Individual Differences, 40(8), 1659-69. [DOI:10.1016/j. paid.2005.12.009]

Garnefski, N., \& Kraaij, V. (2007). The cognitive emotion regulation questionnaire. European Journal of Psychological Assessment, 23(3), 141-9. [DOI:10.1027/1015-5759.23.3.141]

Harmon-Jones, E., Harmon-Jones, C., Abramson, L., \& Peterson C. K. (2009). PANAS positive activation is associated with anger. Emotion, 9(2), 183-96. [DOI:10.1037/a0014959] [PMID]

Hasani, J. (2011). [The reliability and validity of the short form of the cognitive emotion regulation questionnaire (Persian)] Journal of Research in Behavioural Sciences, 9(4), 229-40.

Kim-Spoon, J., Cicchetti, D., \& Rogosch, F. A. (2013). A longitudinal study of emotion regulation, emotion lability-negativity, and internalizing symptomatology in maltreated and nonmaltreated children. Child Development, 84(2), 512-27. [DOI:10.1111/j.1467-8624.2012.01857.x] [PMID] [PMCID]

Krueger, R. F. (1999). Personality traits in late adolescence predict mental disorders in early adulthood: A perspectiveepidemiological study. Journal of Personality, 67(1), 39-65. [DOI:10.1111/1467-6494.00047] [PMID]

Megargee, E. I. (1966). Undercontrolled and overcontrolled personality types in extreme antisocial aggression. Psychological Monographs: General and Applied, 80(3), 1-29. [DOI:10.1037/ h0093894] [PMID]

Mennin, D. S., Heimberg, R. G., Turk, C. L., \& Fresco, D. M. (2005). Preliminary evidence for an emotion dysregulation model of generalized anxiety disorder. Behaviour Research and Therapy, 43(10), 1281-310. [DOI:10.1016/j.brat.2004.08.008] [PMID]

Mennin, D. S., Holaway, R. M., Fresco, D. M., Moore, M. T, \& Heimberg, R. G. (2007). Delineating components of emotion and its dysregulation in anxiety and mood psychopathology. Behavior Therapy, 38(3), 284-302. [DOI:10.1016/j. beth.2006.09.001] [PMID] 
Miller, J. D., \& Lynam, D. R. (2006). Reactive and proactive aggression: Similarities and differences. Personality and Individual Differences, 41(8), 1469-80. [DOI:10.1016/j.paid.2006.06.004]

Miller, J. D., Zeichner, A., \& Wilson, L. F. (2012). Personality correlates of aggression: Evidence from measures of the five-factor model, UPPS model of impulsivity, and BIS/BAS. Journal of Interpersonal Violence, 27(14), 2903-19. [DOI:10.1177/0886260512438279] [PMID]

Norström, T., \& Pape, H. (2010). Alcohol, suppressed anger and violence. Addiction, 105(9), 1580-6. [DOI:10.1111/j.13600443.2010.02997.x] [PMID]

Roberton, T., Daffern, M., \& Bucks, R. S. (2012). Emotion regulation and aggression. Aggression and Violent Behavior, 17(1), 72-82. [DOI:10.1016/j.avb.2011.09.006]

Rydell, R. J., Mackie, D. M., Maitner, A. T., Claypool, H. M., Ryan, M. J., \& Smith, E. R. (2008). Arousal, processing, and risk taking: Consequences of intergroup anger. Personality and Social Psychology Bulletin, 34(8), 1141-52. [DOI:10.1177/0146167208319694] [PMID]

Tull, M. T., Barrett, H. M., McMillan, E. S., \& Roemer, L. (2007). A preliminary investigation of the relationship between emotion regulation difficulties and posttraumatic stress symptoms. Behavior Therapy, 38(3), 303-13. [DOI:10.1016/j. beth.2006.10.001] [PMID]

Waldman, I. D., Singh, A. L., \& Lahey, B. B. (2006). Dispositional Dimensions and the Causal Structure of Child and Adolescent Conduct Problems. In R. F. Krueger \& J. L. Tackett (Eds.) Personality and Psychopathology (pp. 112-152). New York: Guilford Press.

Watson, D., \& Clark, L. A. (1984). Negative affectivity: The disposition to experience aversive emotional states. Psychological Bulletin, 96(4), 465-90. [DOI:10.1037/0033-2909.96.3.465] [PMID]

Watson, D., Clark, L. A., \& Tellegen, A. (1988). Development and validation of brief measures of positive and negative affect: The PANAS scales. Journal of Personality and Social Psychology, 54(6), 1063-70. [DOI:10.1037/0022-3514.54.6.1063] [PMID]

Werner, K., \& Gross, J. J. (2010). Emotion regulation and psychopathology: A conceptual framework. In A. M. Kring \& D. M Sloan (Eds.), Emotion Regulation and Psychopathology: A Transdiagnostic Approach to Etiology and Treatment (pp. 13-37). New York: Guilford Press.

White, B. A., \& Turner, K. A. (2014). Anger rumination and effortful control: Mediation effects on reactive but not proactive aggression. Personality and Individual Differences, 56, 186-9. [DOI:10.1016/j.paid.2013.08.012]

Wyckoff, J. P. (2016). Aggression and emotion: Anger, not general negative affect, predicts desire to aggress. Personality and Individual Differences, 101, 220-6. [DOI:10.1016/j. paid.2016.06.001] 